\title{
BMJ Open Prevalence and risk factors of physical inactivity among middle-aged and older Chinese in Shenzhen: a cross-sectional study
}

\author{
Yanfeng Zhou, ${ }^{1,2}$ Jiang Wu, ${ }^{3}$ Shenchao Zhang, ${ }^{3}$ Shijiao Yan, ${ }^{1}$ Liping $\mathrm{He},{ }^{2}$ \\ Naomie Mkandawire, ${ }^{1}$ Xinyue Song, ${ }^{1}$ Yong Gan, ${ }^{1}$ Wenzhen $\mathrm{Li},{ }^{1}$ Tingting Yang, \\ Jing $\mathrm{Li}^{1}{ }^{1}$ Xiaozhou Zeng, ${ }^{3}$ Zhihong Wang, ${ }^{4}$ Zuxun $\mathrm{Lu}^{1}$
}

To cite: Zhou Y, Wu J, Zhang S, et al. Prevalence and risk factors of physical inactivity among middle-aged and older Chinese in Shenzhen: a crosssectional study. BMJ Open 2018;8:e019775. doi:10.1136/ bmjopen-2017-019775

- Prepublication history and additional material for this paper are available online. To view these, please visit the journal online (http://dx.doi.org/10. 1136/bmjopen-2017-019775).

YZ and JW contributed equally. ZW and ZL contributed equally.

Received 29 September 2017 Revised 30 August 2018 Accepted 4 September 2018

\section{Check for updates}

(C) Author(s) (or their employer(s)) 2018. Re-use permitted under CC BY-NC. No commercial re-use. See rights and permissions. Published by BMJ.

${ }^{1}$ Department of Social Medicine and Health Management, School of Public Health, Tongji Medical College, Huazhong University of Science and Technology, Wuhan, China

${ }^{2}$ Department of Epidemiology and Health Statistics, School of Public Health, Xiangnan University, Chenzhou, China 'Bao'an Central Hospital of Shenzhen, Shenzhen, China ${ }^{4}$ Department of Neurosurgery, Shenzhen Second People's Hospital, Shenzhen University, Shenzhen, China

Correspondence to Professor Zuxun Lu; zuxunlu@yahoo.com

\section{ABSTRACT}

Objective Investigations on physical inactivity are common around the world; however, little is known about the status of physical inactivity in mainland China. The aim of this study was to examine the prevalence and risk factors associated with physical inactivity in Shenzhen in Southern China.

Design A community-based, cross-sectional study. Setting A multistage-stratified, random cluster survey was conducted in Xixiang Street, Bao'an District of Shenzhen in Southeast China.

Participants 3920 adults aged 40 years or more were recruited to the study and completed the International Physical Activity Questionnaire Short Form between 1 March 2015 and 30 July 2016.

Main outcome measures Physical inactivity was defined as engaging in physical activity levels insufficient to reach the current guidelines. Bivariate and multivariate analyses were undertaken to assess the prevalence and risk factors associated with physical inactivity.

Results The prevalence of physical inactivity was $63.1 \%$ for all participants, $63.9 \%$ for women and $61.9 \%$ for men, respectively. Participants who were older $(\mathrm{OR}=1.31,95 \%$ $\mathrm{Cl} 1.11$ to 1.54$)$, who were female $(\mathrm{OR}=1.22,95 \% \mathrm{Cl} 1.04$ to 1.43$)$, who had higher education experience $(\mathrm{OR}=1.38$, $95 \% \mathrm{Cl} 1.19$ to 1.61 ), who are under economic pressure (OR=2.17, 95\% Cl 1.48 to 3.17), who ever smoked a cigarette $(\mathrm{OR}=1.44,95 \% \mathrm{Cl} 1.13$ to 1.82$)$ and drank alcohol $(\mathrm{OR}=1.42,95 \% \mathrm{Cl} 1.14$ to 1.77$)$, and participants in the lowest body mass index category $(\mathrm{OR}=1.40,95 \% \mathrm{Cl}$ 1.03 to 1.89 ), were more likely to report physical inactivity. Conclusions These findings indicate that physical inactivity is prevalent in Southern China. Interventions and programmes aimed at increasing physical activity among middle-aged and older Chinese adults may also be tailored to participants under economic pressure and those with unhealthy behaviours such as smoking and drinking.

\section{INTRODUCTION}

Physical inactivity, defined as insufficient levels of activity to meet recommendations, ${ }^{1}$ is now identified as the fourth leading risk factor for global mortality. Scientific evidence
Strengths and limitations of this study

- Information about differences in physical inactivity levels and associated variables in general Chinese population is limited.

- The design of this cross-sectional study allowed the objective assessment of the prevalence and risk factors associated with physical inactivity in Shenzhen in Southern China.

- Physical inactivity was measured by the International Physical Activity Questionnaire, which provided convenience for international scholars to evaluate global physical inactivity levels.

- The study enrolled only community residents in Shenzhen, limiting the generalisability of findings to other geographical regions.

shows that physical inactivity increases the risk of many adverse health conditions, including major non-communicable diseases. ${ }^{12}$ Worldwide, it is estimated that physical inactivity caused approximately $20 \%$ of the burden of disease from breast and colon cancers, $7 \%$ of type 2 diabetes and $6 \%$ of coronary heart disease. $^{3}$ The WHO Member States in World Health Assembly (WHA66.10) ${ }^{4}$ have agreed on a voluntary global non-communicable chronic disease target for a reduction of $10 \%$ in physical inactivity by 2025 .

Despite compelling evidence for a causal association between physical inactivity and various health outcomes, ${ }^{3}$ the number of studies showed that physical inactivity is common all over the world. Data from 122 countries showed that $31.1 \%$ of adults (aged 15 years or older) were physically inactive, with a range of $4.7 \%$ (Bangladesh) to $71.9 \%$ (Malta). ${ }^{5}$ In Brazil, a population-based, cross-sectional study among 3182 adults aged 20 years or more revealed that the prevalence of physical inactivity was $41.1 \% .^{6}$ In USA, a 
survey of adults (aged 18 years and older) reported that $48.4 \%$ did not engage in physical activity sufficient to meet the aerobic activity guideline. ${ }^{7}$

In Taiwan, a study of 15390 adults found that approximately 4 out of 5 individuals failed to reach the goal of being physically active (expending $750 \mathrm{kcal} /$ week) ${ }^{8} \mathrm{Ku}$ et a $\hat{\theta}$ draw data from four national surveys comprising 29226 people and revealed that $86.0 \%$ of Taiwanese adults did not meet the national recommendations (at least $90 \mathrm{~min} /$ week spent in exercise/sports). Pan et $a l^{10}$ reported that, among 4018 Taiwanese older adults, $47.8 \%$ of the respondents had a high probability of being physically inactive $(<90 \mathrm{~min} /$ week). Elsewhere in mainland China, Lee $e t a l^{11}$ conducted a study focused on 61582 urban men in Shanghai and found that $10.7 \%$ did not engage in regular exercise/sports (at least once a week for at least 3 months). Hu et $a l^{12}$ conducted a study of 3976 people in urban areas of Tianjin and found that more than $60.0 \%$ of the participants reported an absence of physical activity during the preceding 30 days $(<1$ time per month).

Understanding the factors associated with physical inactivity can help us take pertinent interventions on targeted populations and increase the levels of physical activity. Although previous studies found that physical inactivity was associated with demographic variables (such as gender, age, weight, education) ${ }^{13-15}$ and health behaviours (such as smoking and drinking), ${ }^{16}$ little is known about how physical inactivity varies across a number of factors among middle-aged and older Chinese adults. Therefore, we conducted this cross-sectional study to examine the prevalence and determinants of physical inactivity among community residents aged above 40 years in Shenzhen, China.

\section{METHODS}

\section{Patient and public involvement}

This community-based, cross-sectional study was conducted between 1 March 2015 and 30 July 2016, in Xixiang Street, Bao'an District of Shenzhen in Southeast China. The reasons for selecting Xixiang Street were written by the China National Stroke Prevention Project. ${ }^{17}$ Xixiang Street had 33 communities. We selected three communities (TaoyuanJu, Liutang, Xixiang) that met the following eligibility criteria: (1) medical staffs in community health service centre had high enthusiasm of participation in health education programmes; (2) health records were well presented; and (3) in the national chronic disease comprehensive prevention and control demonstration zone or national disease surveillance spot. Then, in each community, a multistage-stratified, random cluster survey was conducted. At the first stage of sampling, a total of 4202 households in three communities were randomly chosen using a computer program. Households were involved in participation if family members met the following criteria: (1) permanent residents (living in this district for at least 6 months each year) who could be contacted and aged 40 years and above; and (2) participants without mental disorders and agreed to attend in this survey. At the second stage of sampling, one eligible participant was randomly selected in each contacted household to act as the respondent for the interview. Finally, all eligible participants were registered at the local government and informed to do physical and laboratory examinations in community health centres at a specific time. Participants were allowed to obtain the results from the community health centres 2 weeks later.

\section{Data collection}

Following the study protocol, the investigators were trained by the Health Bureau of Bao'an District and Shenzhen Second People's Hospital. Then the data were collected by trained investigators in the community health centre, using a standardised questionnaire during face-toface interviews. The questionnaires covered demographic characteristics, physical activity levels, health status and health risk factors. After the interview, a series of physical measurements including weight, height, blood pressure and fasting plasma glucose (FPG) were recorded for each participant by trained technicians.

\section{Measuring physical activity}

In this study, the translated Chinese International Physical Activity Questionnaire (IPAQ) short version was used to assess physical activity levels. Detailed descriptions of the translated Chinese IPAQ short version have been previously reported. ${ }^{18}$ The number of hours spent in undertaking four types of physical activity (vigorous physical activity, moderate physical activity, walking and sitting) per week was recorded in the IPAQ Short Form. Definitions of vigorous (such as heavy lifting, digging, aerobics or fast bicycling) and moderate activities (such as carrying light loads, bicycling at a regular place or tennis doubles) were provided to the respondents. Only those physical activities for more than $10 \mathrm{~min}$ at a time were included. The IPAQ Short Form also assessed the time spent sitting (sedentary time) on a weekday during the previous week.

\section{Explanatory variables}

Most of the variables were self-explanatory, but a few needed explanation. Age groups were defined based on age decades. The question 'Is your monthly income sufficient to cover all your basic needs' was asked to identify whether participants were under economic pressure. Mental stress was defined as a yes or no response to a question asking whether the participant experienced any stress in the workplace or daily life. Smoking was defined as having smoked at least one cigarette per day in the last 3 months. Alcohol intake was defined as drinking $\geq 100 \mathrm{~mL}$ spirit alcohol more than three times per week in the last 3 months based on self-report. Body mass index (BMI) was calculated as weight in kilograms divided by height in metres squared $(\mathrm{kg} /$ $\mathrm{m}^{2}$ ). Based on the WHO BMI classification for adults, 
participants were classified as underweight $(\mathrm{BMI}<18.5$ $\left.\mathrm{kg} / \mathrm{m}^{2}\right)$, normal weight $\left(18.5 \leq \mathrm{BMI}<25.0 \mathrm{~kg} / \mathrm{m}^{2}\right)$, overweight $\left(25.0 \leq \mathrm{BMI}<30.0 \mathrm{~kg} / \mathrm{m}^{2}\right)$ or obese $(\mathrm{BMI} \geq 30.0 \mathrm{~kg}$ / $\mathrm{m}^{2}$ ). Hypertension was defined as resting systolic blood pressure $\geq 140 \mathrm{~mm} \mathrm{Hg}$ and/ordiastolic blood pressure $\geq 90 \mathrm{~mm} \mathrm{Hg}$, or use of antihypertensive drugs. In our study, diabetes mellitus was defined as $\mathrm{FPG} \geq 7.0 \mathrm{mmol} / \mathrm{L}$ or use of medication for diabetes.

\section{Statistical analysis}

All statistical procedures were performed using the SPSS V.18.0 software. The prevalence of physical inactivity was presented and $\chi^{2}$ test was conducted to test the differences between groups. Both unadjusted and adjusted logistic regression analyses were performed to identify the determinants of physical inactivity. The unadjusted method used only the key factors of interest as independent variables in the analysis, while the adjusted method added all of the possible confounders listed in table 1 as covariates in the logistic models. ORs and 95\% CIs for each variable were calculated. Tests for interaction were conducted by adding interaction terms of gender and the covariate in the final model. Statistical significance was accepted at $\mathrm{p}<0.05$.

\section{RESULTS}

The main characteristics of the participants are presented in table 1. A total of 4202 participants were investigated in this study, and data from 282 questionnaires were excluded due to missing information. Finally, 3920 (2447 women, $62.4 \%$ ) eligible participants were included in the analysis, with a mean age of 54.28 years and a mean BMI of 24.70. Overall, the prevalence of physical inactivity was $63.1 \%$. Notably, participants who were young, who had lower education experiences, who were under economic pressure and mental stress, and who had slightly higher BMI had a higher level of physical inactivity.

Unadjusted and adjusted ORs and 95\% CIs for the results of logistic regression are presented in table 2. Unadjusted logistic regression showed that participants who were older (OR: $1.37,95 \%$ CI 1.16 to 1.61 ), who were female (OR: $1.20,95 \%$ CI 1.02 to 1.41 ), who had higher education experience (OR: $1.41,95 \%$ CI 1.21 to $1.64)$, who were under economic pressure (OR: 2.22, 95\% CI 1.52 to 3.25 ), who had smoked cigarettes (OR: $1.45,95 \%$ CI 1.15 to 1.84$)$ and drank alcohol $(\mathrm{OR}=1.40$, $95 \%$ CI 1.13 to 1.75 ) were more likely to report physical inactivity. After adjusting for history of hypertension, diabetes and stroke, the only difference was with BMI status. Participants in the lowest BMI category were more likely (OR: $1.40,95 \%$ CI 1.03 to 1.89 ) to report physical inactivity than participants in the highest BMI category.

Additional information regarding the effects of gender on physical inactivity is shown in online supplementary table S1. Most of the results on the factors associated with physical inactivity for women were consistent with that of the factors associated with physical inactivity for men.
Table 1 Sociodemographic characteristics of the studied population $(n=3920)$

\begin{tabular}{|c|c|c|c|}
\hline Characteristics & Total (\%) & $\begin{array}{l}\text { Physical } \\
\text { inactivity (\%) }\end{array}$ & P values* \\
\hline Age group (years) & & & $<0.001$ \\
\hline $40-49$ & $1426(36.4)$ & $966(67.7)$ & \\
\hline $50-59$ & 1346 (34.3) & $829(61.6)$ & \\
\hline $60+$ & $1148(29.3)$ & $680(59.2)$ & \\
\hline Gender & & & 0.219 \\
\hline Female & $2447(62.4)$ & 1563 (63.9) & \\
\hline Male & $1473(37.6)$ & 912 (61.9) & \\
\hline Ethnicity & & & 0.668 \\
\hline Han nationality & 3825 (97.6) & 2417 (63.2) & \\
\hline Non-Han nationality & $95(2.4)$ & $58(61.1)$ & \\
\hline Education level & & & 0.012 \\
\hline$\leq 6$ years $\uparrow$ & $1263(32.4)$ & $830(65.7)$ & \\
\hline$>6$ years & $2631(67.6)$ & $1620(61.6)$ & \\
\hline Marital status & & & $<0.001$ \\
\hline Married & 3753 (95.7) & $2341(62.4)$ & \\
\hline $\begin{array}{l}\text { Unmarried/widow/ } \\
\text { divorced }\end{array}$ & $167(4.3)$ & $134(80.2)$ & \\
\hline
\end{tabular}

\begin{tabular}{|lrr|}
\hline Economic pressure & & $<0.001$ \\
\hline Yes & $580(14.8)$ & $477(82.2)$ \\
No & $3340(85.2)$ & $1998(59.8)$
\end{tabular}

$\begin{array}{lrrr}\text { Mental stress } & & <0.001 \\ \text { Yes } & 634(16.2) & 504(79.5) & \\ \text { No } & 3286(83.8) & 1971(60.0)\end{array}$

\begin{tabular}{|crrr} 
Smoking status & & $<0.001$ \\
\hline Ever & $448(11.4)$ & $240(53.6)$ & \\
\hline Never & $3448(88.0)$ & $2219(64.4)$ & \\
\hline Unknown & $24(0.6)$ & $16(66.7)$ & \\
Alcohol drinking & & & $<0.001$ \\
\hline Ever & $461(11.8)$ & $238(51.6)$ & \\
\hline Never & $2808(71.6)$ & $1718(61.2)$ & \\
\hline Unknown & $651(16.6)$ & $519(79.7)$ & \\
\hline BMl (kg/m $\left.{ }^{2}\right)$ & & & 0.007 \\
\hline$<25.0$ & $2038(52.0)$ & $1239(60.8)$ & \\
\hline $25.0-29.9$ & $1653(42.2)$ & $1084(65.6)$ & \\
\hline $30.0+$ & $229(5.8)$ & $152(66.4)$ & \\
\hline
\end{tabular}

History of $\quad<0.001$

hypertension

$\begin{array}{lrrr}\text { Yes } & 858(21.9) & 471(54.9) & \\ \text { No } & 3058(78.1) & 2000(65.4) & \\ \text { History of diabetes } \neq & & & <0.001 \\ \text { Yes } & 324(8.3) & 174(53.7) & \\ \text { No } & 3593(91.7) & 2299(64.0) & \\ \text { History of stroke } & & & 0.002 \\ \text { Yes } & 135(3.4) & 68(50.4) & \\ \text { No } & 3785(96.6) & 2407(63.6) & \end{array}$

Continued 


\begin{tabular}{|c|c|c|c|}
\hline Characteristics & Total (\%) & $\begin{array}{l}\text { Physical } \\
\text { inactivity (\%) }\end{array}$ & P values* \\
\hline Communities & & & 0.488 \\
\hline TanyuanJu & 1307 (33.3) & $830(33.5)$ & \\
\hline Liutang & 1307 (33.3) & $837(33.8)$ & \\
\hline Xixiang & 1306 (33.3) & 808 (32.6) & \\
\hline
\end{tabular}

${ }^{*} \chi^{2}$ test of heterogeneity.

†Defined as illiterate or having only finished primary education.

$\ddagger$ Confirmed diagnosis of type 1 or 2 diabetes mellitus on admission.

BMI, body mass index.

However, men who smoked cigarettes and drank alcohol had a higher level of physical inactivity; nevertheless, such associations were not found in women $(\mathrm{p}<0.05$ for interaction; online supplementary table $\mathrm{S} 1$ ).

\section{DISCUSSION}

We assessed the status of physical inactivity and associated variables among community residents in Shenzhen, China, indicating that the overall prevalence of physical inactivity in community residents aged more than 40 years was $63.1 \%$. Since the definitions of physical inactivity might vary by country and region, we just included relevant literatures that used a similar definition of physical inactivity for comparison. Physical inactivity was defined as not meeting any of the three criteria: $30 \mathrm{~min}$ of moderate-intensity physical activity on at least 5 days every week, $75 \mathrm{~min}$ of vigorous-intensity aerobic physical activity throughout the week or an equivalent combination. Our results showed that the prevalence of physical inactivity was higher than previously reported in other countries. In Americas, ${ }^{5}$ Brazil,${ }^{6}$ Thailand ${ }^{19}$ and Mexico, ${ }^{20}$ the prevalence of physical inactivity was $43.3 \%, 41.1 \%, 26.0 \%$ and $19.4 \%$, respectively.

The findings of our study revealed that there was a moderate association between older age and physical inactivity, which was in line with the findings of previous studies, ${ }^{61621}$ but was inconsistent with other studies. ${ }^{22}$ It is likely that older people may have higher comorbidities which may limit their participation in physical activity. ${ }^{23}$ Similar to some studies, ${ }^{24} 25$ our data revealed that individuals with higher education experience were more likely to report physical inactivity. One possible explanation was that higher educated individuals were primarily engaged in brainwork or light manual labour, and sedentary behaviours are given priority in their life. Moreover, several studies had shown that the populations with lower socioeconomic status tended to have lower physical inactivity level. ${ }^{6}$ Our results showed that participants under economic pressure were 2.17 times more likely to report physical inactivity than those without economic pressure. Lower socioeconomic status generally implies poorer life opportunities. People with lower socioeconomic status might live in more deprived neighbourhoods with fewer exercise facilities ${ }^{26}$ and have fewer chances to improve or maintain one's health.

A considerable number of studies have examined the relationship between BMI and physical inactivity, but the results remain equivocal. Sorkin $e t a l^{27}$ found that all types of self-reported physical activities were associated with lower BMI, and Schneider and Becker ${ }^{21}$ showed that overweight people were significantly less likely to engage in physical activity. However, Steele $e t a t^{28}$ reported no relationship between moderate physical activity and BMI or fat mass index in British children. In our analysis, we found that normal-weight or underweight people had a higher level of physical inactivity, which may be due to the fact that weight management was influenced by energy intake and energy expenditure, and both important components should be considered simultaneously. ${ }^{29}$ Additionally, one of the benefits of physical activity for older adults is a healthier body mass and composition according to WHO. ${ }^{1}$ Thus, more educational programmes and intervention measures for reducing the prevalence of physical inactivity should be targeted to the obese group and also to the general population.

It has been reported that lifestyle behaviours are interrelated and that unhealthy behaviours tend to occur together. ${ }^{24}$ In this study, we found that people who smoked cigarettes or drank alcohol were more likely to report physical inactivity than people who did not smoke cigarettes or drink alcohol, which was in line with published literatures. ${ }^{212430}$ To our knowledge, physical inactivity is more common in women than in men in most countries. ${ }^{19}$ We did the gender-covariate interactions tests to explore whether there were different risk factors among men and women, and found that smoking cigarettes and drinking alcohol were significantly associated with physical inactivity level in men but not in women. The possible reason for this finding may be that the proportion of women who smoked cigarettes and drank alcohol in China was relatively lower than men. In this study, the proportion of women who smoked cigarettes and drank alcohol was $0.8 \%$ and $5.0 \%$, respectively, while the proportion of men who smoked cigarettes and drank alcohol reached up to $29.1 \%$ and $23.0 \%$, respectively. These results suggest that health education activities on tobacco smoking control and moderate alcohol drinking are needed to achieve healthy lifestyle behaviours.

The major strength of our study was that we assessed physical inactivity using the IPAQ Short Form, which was developed as a standardised process for participants to assess the prevalence of physical inactivity and provided convenience for international scholars to evaluate global physical inactivity levels. Our study also has some limitations. First, although the IPAQ Short Form included vigorous physical activity, moderate physical activity, walking and sitting, individuals were not prompted to answer separately about each category (leisure time, work, transportation and household), and therefore some activities could be omitted. ${ }^{31}$ 
Table 2 Logistic regression model of potential determinants of physical inactivity

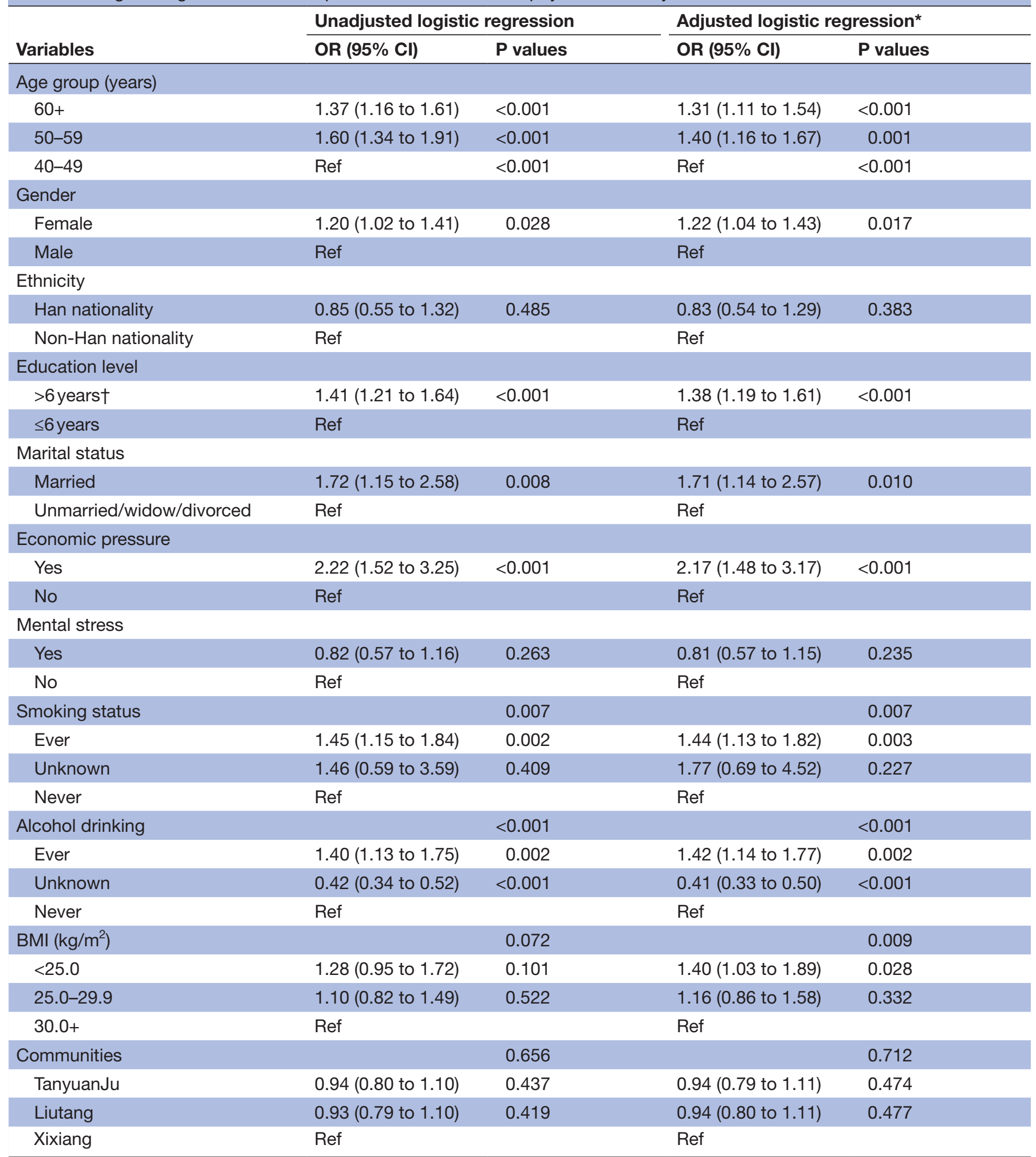

*Adjusted for all variables shown in the table plus history of hypertension, diabetes and stroke.

†Defined as illiterate or having only finished primary education.

BMI, body mass index; Ref, referent.

Second, as a self-report measure, recall bias could not be avoided and the accuracy of estimates of frequency, duration and intensity could be compromised. Thus, new technologies and device-based measures, such as pedometers and other electronic movement-sensing devices, could be used together with IPAQ to accurately assess the prevalence of physical inactivity. ${ }^{32} 33$ Third, this study enrolled only community residents 
in Shenzhen, limiting the generalisability of finding to other geographical regions.

\section{CONCLUSIONS}

In conclusion, this study suggests that the prevalence of physical inactivity in urban Chinese is high, and great efforts must be made to achieve the WHO goal for a reduction of $10 \%$ in physical inactivity by 2025 . Interventions and programmes aimed at increasing physical activity among middle-aged and older Chinese adults may also be tailored to participants under economic pressure and those with unhealthy behaviours such as smoking and drinking.

Acknowledgements The authors thank the Health Bureau of Bao'an District and the community health centre of Bao'an Central Hospital of Shenzhen for participating in the study. The authors also thank all study participants who have been involved in and contributed to data collection.

Contributors ZL, ZW, YZ and JW conceived the study and drafted the manuscript. YZ and JW searched the scientific literature, and carried out the most work including study selection, statistic analyses, and data collection and interpretation. SZ, TY, WL, JL and XZ participated in data collection and interpretation. XS and YG participated in the design of data synthesis and analysis. NM, SY and LH gave administrative, technical or material support, and made important revisions to the draft manuscript. ZL and ZW helped to resolve the disagreements and checked the data. All authors have seen and approved the final version.

Funding This study was supported by the National Natural Science Foundation of China (Study on the gatekeeper policy of CHS, 71373090) and the Fundamental Research Funds for the Central Universities (Huazhong University of Science and Technology, 2016YXMS215).

Competing interests None declared.

Patient consent Obtained.

Ethics approval This study was approved by the Research Ethics Committee in Tongji Medical College, Huazhong University of Science and Technology, Wuhan, China.

Provenance and peer review Not commissioned; externally peer reviewed.

Data sharing statement Researchers who are interested in the data set can contact the corresponding author (ZL) (email: zuxunlu@yahoo.com; tel and fax: +86 27 83693756) or the Community Health Service Management Center in Xixiang (email: chsmc_xixiang@163.com; tel and fax: +86 755 27791243) to acquire the data for research only.

Open access This is an open access article distributed in accordance with the Creative Commons Attribution Non Commercial (CC BY-NC 4.0) license, which permits others to distribute, remix, adapt, build upon this work non-commercially, and license their derivative works on different terms, provided the original work is properly cited, appropriate credit is given, any changes made indicated, and the use is non-commercial. See: http://creativecommons.org/licenses/by-nc/4.0/.

\section{REFERENCES}

1. World Health Organization. Global recommendations on physical activity for health. Geneva: World Health Organization, 2010. http:// www.who.int/iris/handle/10665/44399 (accessed 6 May 2018).

2. World Health Organization. Global health risks: mortality and burden of disease attributable to selected major risks. Geneva: World Health Organization, 2009.

3. Lee IM, Shiroma EJ, Lobelo F, et al. Effect of physical inactivity on major non-communicable diseases worldwide: an analysis of burden of disease and life expectancy. Lancet 2012;380:219-29.

4. Resolution WHA 66.10. Follow up to the political declaration of the high-level meeting of the general assembly on the prevention and control of non-communicable disease. Geneva: World Health Organization, 2013. http://apps.who.int/gb/ebwha/pdf_files/WHA66REC1/A66_REC1-en.pdf\#page=25 (accessed 6 May 2018).
5. Hallal PC, Andersen LB, Bull FC, et al. Global physical activity levels: surveillance progress, pitfalls, and prospects. Lancet 2012;380:247-57.

6. Hallal PC, Victora CG, Wells JC, et al. Physical inactivity: prevalence and associated variables in Brazilian adults. Med Sci Sports Exerc 2003;35:1894-900.

7. Harris CD, Watson KB, Carlson SA, et al. Adult participation in aerobic and muscle-strengthening physical activities-United States, 2011. MMWR Morb Mortal Wkly Rep 2013;62:326-30.

8. Wai JP, Wen CP, Chan HT, et al. Assessing physical activity in an Asian country: low energy expenditure and exercise frequency among adults in Taiwan. Asia Pac J Clin Nutr 2008;17:297-308.

9. Ku PW, Fox KR, McKenna J, et al. Prevalence of leisure-time physical activity in Taiwanese adults: results of four national surveys, 20002004. Prev Med 2006;43:454-7.

10. Pan LY, Hsu HC, Chang WC, et al. Trajectories of physical activity and risk factors among Taiwanese older adults. Int J Behav Med 2015;22:62-9.

11. Lee SA, Xu WH, Zheng W, et al. Physical activity patterns and their correlates among Chinese men in Shanghai. Med Sci Sports Exerc 2007;39:1700-7.

12. Hu G, Pekkarinen $\mathrm{H}$, Hänninen $\mathrm{O}$, et al. Physical activity during leisure and commuting in Tianjin, China. Bull World Health Organ 2002;80:933-8.

13. Liu J, Wade T, Faught BE, et al. Physical inactivity in Canada: results from the Canadian Community Health Survey Cycle 2.2 (2004-2005). Public Health 2008;122:1384-6.

14. Drygas W, Kwaśniewska M, Kaleta D, et al. Epidemiology of physical inactivity in Poland: prevalence and determinants in a former communist country in socioeconomic transition. Public Health 2009;123:592-7.

15. Abubakari AR, Lauder W, Jones MC, et al. Prevalence and time trends in diabetes and physical inactivity among adult West African populations: the epidemic has arrived. Public Health 2009;123:602-14.

16. Florindo AA, Guimarães VV, Cesar CL, et al. Epidemiology of leisure, transportation, occupational, and household physical activity: prevalence and associated factors. J Phys Act Health 2009;6:625-32.

17. Gan Y, Wu J, Zhang S, et al. Prevalence and risk factors associated with stroke in middle-aged and older Chinese: a community-based cross-sectional study. Sci Rep 2017;7:9501.

18. Deng HB, Macfarlane DJ, Thomas GN, et al. Reliability and validity of the IPAQ-Chinese: the Guangzhou biobank cohort study. Med Sci Sports Exerc 2008;40:303-7.

19. Thanamee S, Pinyopornpanish K, Wattanapisit A, et al. A populationbased survey on physical inactivity and leisure time physical activity among adults in Chiang Mai, Thailand, 2014. Arch Public Health 2017;75:41.

20. Medina C, Janssen I, Campos I, et al. Physical inactivity prevalence and trends among Mexican adults: results from the National Health and Nutrition Survey (ENSANUT) 2006 and 2012. BMC Public Health 2013;13:1063.

21. Schneider S, Becker S. Prevalence of physical activity among the working population and correlation with work-related factors: results from the first German National Health Survey. J Occup Health 2005;47:414-23.

22. Bauman A, Ma G, Cuevas F, et al. Cross-national comparisons of socioeconomic differences in the prevalence of leisure-time and occupational physical activity, and active commuting in six AsiaPacific countries. J Epidemiol Community Health 2011;65:35-43.

23. Crespo CJ, Smit E, Andersen RE, et al. Race/ethnicity, social class and their relation to physical inactivity during leisure time: results from the Third National Health and Nutrition Examination Survey, 1988-1994. Am J Prev Med 2000;18:46-53.

24. Pomerleau J, McKee M, Robertson A, et al. Physical inactivity in the baltic countries. Prev Med 2000;31:665-72.

25. Wagner A, Simon C, Evans A, et al. Physical activity patterns in 50-59 year men in France and Northern Ireland. Associations with socio-economic status and health behaviour. Eur J Epidemiol 2003;18:321-9.

26. Estabrooks PA, Lee RE, Gyurcsik NC. Resources for physical activity participation: does availability and accessibility differ by neighborhood socioeconomic status? Ann Behav Med 2003;25:100-4.

27. Sorkin DH, Biegler KA, Billimek J. Differences in self-reported physical activity and body mass index among older hispanic and non-hispanic white men and women: findings from the 2009 California health interview survey. J Am Geriatr Soc 2015;63:2158-63.

28. Steele RM, van Sluijs EM, Cassidy A, et al. Targeting sedentary time or moderate- and vigorous-intensity activity: independent relations 
with adiposity in a population-based sample of 10 -y-old British children. Am J Clin Nutr 2009;90:1185-92.

29. Jalali-Farahani S, Amiri P, Chin YS. Are physical activity, sedentary behaviors and sleep duration associated with body mass index-forage and health-related quality of life among high school boys and girls? Health Qual Life Outcomes 2016;14:30.

30. Burton NW, Turrell G. Occupation, hours worked, and leisure-time physical activity. Prev Med 2000;31:673-81.
31. Hallal PC, Victora CG, Wells JCK, et al. Comparison of short and full-length international physical activity questionnaires. J Phys Act Health 2004;1:227-34.

32. van Poppel MN, Chinapaw MJ, Mokkink LB, et al. Physical activity questionnaires for adults: a systematic review of measurement properties. Sports Med 2010;40:565-600.

33. Troiano RP, Pettee Gabriel KK, Welk GJ, et al. Reported physical activity and sedentary behavior: why do you ask? J Phys Act Health 2012;9(Suppl 1):S68-S75. 